\title{
Storage Effect on the Shear Bond Strength of Adhesive Systems
}

\author{
Alysson Noriyuki Kajishima KONNO \\ Mário Alexandre Coelho SINHORETI \\ Simonides CONSANI \\ Lourenço CORRER SOBRINHO \\ Rafael Leonardo Xediek CONSANI
}

Discipline of Dental Materials, Faculty of Dentistry of Piracicaba, UNICAMP, Piracicaba, SP, Brazil

\begin{abstract}
The purpose of this study was to evaluate the effects of storage ( 1 day, 3 months and 6 months) on the shear bond strength of five adhesive systems on bovine dentin substrate. One hundred and fifty bovine incisors were flattened until areas of a minimum of $5 \mathrm{~mm}$ in diameter were exposed. A round area of $4 \mathrm{~mm}$ in diameter was marked on the dentin to be treated with the following adhesive systems: Clearfil Liner Bond 2V (CLB2V), Scotchbond Multi Purpose Plus (SBMP), Optibond Solo (SOLO), Prime \& Bond NT (PBNT) and Etch \& Prime 3.0 (E\&P). To perform the test, a composite restoration (Z100) was made in a cylindrical shape on the treated surface. After the storage period in distilled water at $37^{\circ} \mathrm{C}$, the samples were tested on an Instron testing machine. Results were submitted to ANOVA and Tukey's test at 5\% significance level. SBMP, PBNT and E\&P were statistically similar at all storage times (p>0.05). CLB2V demonstrated the highest mean shear bond strength at 3 months which was not significantly different at 6 months $(p>0.05)$. In addition, CLB2V had the highest means at all times tested. SOLO had the lowest mean shear bond strength at 6 months, which was statistically lower than means at 3 months and 1 day $(\mathrm{p}<0.05)$.
\end{abstract}

Key Words: adhesive systems, bond strength, aging, storage.

\section{INTRODUCTION}

The introduction of the acid etching technique (1) and the development of hydrophilic monomers (2) have made the use of adhesive systems possible in dentistry. Currently, the use of adhesive systems on dentin substrate is more effective. The presence of a hybrid layer $(3,4)$ increases the bond strength and promotes the sealing of dentin surfaces by means of a resin-impregnated zone on decalcified dentin, preventing the microleakage of toxic products and consequently post-operative pain and restoration failure.

The quality of the adhesion to the dentin substrate has been evaluated by laboratory tests such as tensile or shear tests. In 1991, ISO created a specification [Guidance on testing of adhesion to tooth structure. ISO/TC106/SC 1 N236, Resolution 6 1. - CD TR 11405, Trieste, October, 1991] for dentin bond tests which suggests a standard specimen storage period for which durability is analyzed. This standard demon- strates that specimens may be stored in distilled water at $37^{\circ} \mathrm{C}$ for 6 months.

Bonding durability is an important factor for analysis. Buonocore et al. (5) reported that after 3 months storage, a $50 \%$ decrease in bond strength occurred. Kiyomura (6), Kato and Nakabayashi (7) and Burrow et al. (8) also found decreased bond strength in in vitro tests after long storage periods. Sano et al. (9), in an in vivo study performed on monkeys, recorded the degradation of the hybrid layer after 1 year, observing porosity at its base.

The aim of this study was to evaluate the effects of storage (1 day, 3 months and 6 months) on the shear bond strength of five adhesive systems on bovine dentin substrate.

\section{MATERIAL AND METHODS}

Five commercially available adhesive systems and Z-100 composite resin (3M Dental Products, St. 
Paul, MN, USA) were used in this study (Table 1).

One hundred and fifty mandibular bovine incisors were used. Teeth were scaled with a periodontal scaler to remove organic debris before cleaning with water/pumice slurry. After cleaning, teeth were stored in distilled water and cooled to $4^{\circ} \mathrm{C}$ until the beginning of the test. Crowns were cut at approximately $0.5 \mathrm{~cm}$ from the cementum-enamel edge and fixed in plastic cylinders $(20 \mathrm{~mm}$ in diameter and $20 \mathrm{~mm}$ height). Buccal surfaces were filled with auto-curing acrylic resin and were exposed to the external side of the border of the plastic cylinder. Specimens were inserted in a round metallic mould ground and polished using $80,120,220,320$ and 400 grain sandpaper (Carborundum Abrasivos, Recife, PE, Brazil) on an automated polisher APL-4 (Arotec Ind. Com. Ltda., São Paulo, SP, Brazil) under water-cooling until a 5 $\mathrm{mm}$ area of dentin was obtained.

Adhesive tape with a hole in the center ( $4 \mathrm{~mm}$ in diameter) was adhered to the prepared dentin surface, delimiting the area to be used to bond the composite resin. The specimens were then divided into 5 equal groups and the adhesive systems were applied accord-

Table 1. Adhesive systems used and their respective manufacturers.

\begin{tabular}{ll}
\hline Adhesive System & Manufacturer \\
\hline Clearfil Liner Bond 2V (CLB2V) & $\begin{array}{l}\text { Kuraray } \\
\text { Osaka, Japan }\end{array}$ \\
Scotchbond Multi Purpose Plus (SBMP) & $\begin{array}{l}\text { 3M Dental Products } \\
\text { St. Paul, MN, USA }\end{array}$ \\
Optibond Solo (SOLO) & $\begin{array}{l}\text { Kerr Manufac. Co. } \\
\text { Romulus, MI, USA }\end{array}$ \\
Prime \& Bond NT (PBNT) & $\begin{array}{l}\text { Dentsply } \\
\text { Milfort, DE, USA }\end{array}$ \\
Etch \& Prime 3.0 (E\&P) & Degussa Hülls \\
& Hanau, Germany \\
\hline
\end{tabular}

ing to manufacturer instructions.

To build the restoration, a stainless steel round mould, $5 \mathrm{~mm}$ in height with a central hole of $4 \mathrm{~mm}$ in diameter and longitudinally cut, was positioned over the specimens coinciding the central hole with the delimited area on the dentin. Composite resin was inserted in three increments, each one was light cured for $40 \mathrm{~s}$ with a light-curing unit XL-1500 (3M Dental Products, St. Paul, MN, USA). At this point, each of the 5 groups was divided into 3 sub-groups according to the storage time ( 1 day, 3 months and 6 months) in distilled water at $37^{\circ} \mathrm{C}$.

After storage, the specimens were tested for shear bond strength in an Instron 4411 machine (Instron Corporation, Canton, MA, USA) at a crosshead speed of $0.5 \mathrm{~mm} / \mathrm{min}$ until failure occurred. The shear bond test was carried out with a metallic tape $(5 \mathrm{~mm}$ width and $10 \mathrm{~cm}$ length) forming a loop that involved the composite cylinder (10). The means of shear bond strength were determined by the following formula: $\mathrm{S}=\mathrm{T} / \mathrm{A}$, where $\mathrm{S}$ is the shear bond strength, $\mathrm{T}$ is the tension applied, and $\mathrm{A}$ is the bonded area. When the shear test was finished, two representative specimens of each group were coated in gold and examined by scanning electron microscopy (LEO 435, UP, London, UK) at 500X magnification. The results were submitted to analysis of variance and Tukey's test at a significance level of $5 \%$.

\section{RESULTS}

As shown in Table 2, Scotchbond Multi Purpose Plus, Prime \& Bond NT and Etch \& Prime 3.0 were statistically similar at all times ( $p>0.05)$. Clearfil Liner Bond $2 \mathrm{~V}$ had the highest mean at 3 months, which was statistically different from the 1 -day value $(\mathrm{p}<0.05)$. The mean strength at 6 months was statistically similar to those at 1 day and 3 months. The highest means for Optibond Solo were at 1 day and 3 months of storage $(p>0.05)$ and the lowest mean for Optibond Solo

Table 2. Shear bond strength means (MPa) of the adhesive systems in function of storage time.

\begin{tabular}{lccccc}
\hline & CLB2V & SBMP & PBNT & SOLO & E\&P \\
\hline 1day & $6.45 \pm 0.52 \mathrm{~b}$ & $4.14 \pm 0.36 \mathrm{a}$ & $2.12 \pm 0.42 \mathrm{a}$ & $3.22 \pm 0.42 \mathrm{a}$ & $1.06 \pm 0.29 \mathrm{a}$ \\
3 months & $9.27 \pm 0.33 \mathrm{a}$ & $3.28 \pm 0.41 \mathrm{a}$ & $3.89 \pm 0.70 \mathrm{a}$ & $2.93 \pm 0.38 \mathrm{a}$ & $1.43 \pm 0.31 \mathrm{a}$ \\
6 months & $7.69 \pm 0.34 \mathrm{ab}$ & $3.24 \pm 0.87 \mathrm{a}$ & $2.09 \pm 0.49 \mathrm{a}$ & $1.81 \pm 0.63 \mathrm{~b}$ & $0.73 \pm 0.32 \mathrm{a}$
\end{tabular}
was obtained at 6 months, which was statistically different from the values at 1 day and 3 months $(\mathrm{p}<0.05)$.

Table 3 shows

Means followed by same letter in the column indicate no statistical difference at 95\% (Tukey’s test). that, at 1 day, Clearfil 
Liner Bond $2 \mathrm{~V}$ presented the highest shear bond strength, which was significantly different $(p<0.05)$ from the values obtained for the other systems. Scotchbond Multi Purpose Plus was statistically similar to Optibond Solo ( $>0.05)$ and presented a statistically higher mean than Prime \& Bond NT and Etch \& Prime $3.0(\mathrm{p}<0.05)$. Optibond Solo shear bond mean was significantly higher than that of Etch \& Prime 3.0, which presented the lowest means.

At the 3-month period, Clearfil Liner Bond 2V demonstrated the highest shear bond strength, differing statistically from those of the other groups $(p<0.05)$, followed by Prime \& Bond NT, Scotchbond Multi Purpose Plus and Optibond Solo, respectively, which presented no statistical differences among them (p>0.05). Etch \& Prime 3.0 demonstrated the lowest mean, which was statistically different from those of the other systems $(\mathrm{p}<0.05)$.

After 6 months of storage, Clearfil Liner Bond $2 \mathrm{~V}$ presented the highest means, which were statistically different from those of the other systems $(\mathrm{p}<0.05)$,

Table 3. Shear bond strength means (MPa) for each storage time in function of the adhesive systems.

\begin{tabular}{lccc}
\hline & \multicolumn{1}{c}{1 day } & 3 months & 6 months \\
\hline CLB2V & $6.45 \pm 0.52 \mathrm{a}$ & $9.27 \pm 0.33 \mathrm{a}$ & $6.92 \pm 0.35 \mathrm{a}$ \\
SBMP & $4.14 \pm 0.36 \mathrm{~b}$ & $3.28 \pm 0.42 \mathrm{~b}$ & $2.92 \pm 0.87 \mathrm{~b}$ \\
PBNT & $2.12 \pm 0.42 \mathrm{~cd}$ & $3.89 \pm 0.70 \mathrm{~b}$ & $2.09 \pm 0.49 \mathrm{bc}$ \\
SOLO & $3.22 \pm 0.42 \mathrm{bc}$ & $2.93 \pm 0.38 \mathrm{~b}$ & $1.81 \pm 0.63 \mathrm{~cd}$ \\
E\&P & $1.06 \pm 0.29 \mathrm{~d}$ & $1.43 \pm 0.31 \mathrm{c}$ & $0.73 \pm 0.32 \mathrm{~d}$ \\
\hline
\end{tabular}

Means followed by same letter in the column indicate no statistical difference at $95 \%$ (Tukey's test).

Table 4. Failure type percentage found after shear bond testing of the adhesive systems at each storage time.

\begin{tabular}{|c|c|c|c|c|c|c|}
\hline & \multicolumn{2}{|c|}{1 day } & \multicolumn{2}{|c|}{3 months } & \multicolumn{2}{|c|}{6 months } \\
\hline & Adhesive & Mixed & Adhesive & Mixed & Adhesive & Mixed \\
\hline SBMP & 50 & 50 & 90 & 10 & 60 & 40 \\
\hline CLB2V & 40 & 60 & 0 & 100 & 0 & 100 \\
\hline SOLO & 100 & 0 & 100 & 0 & 90 & 10 \\
\hline PBNT & 90 & 10 & 90 & 10 & 90 & 10 \\
\hline E\&P & 100 & 0 & 100 & 0 & 100 & 0 \\
\hline
\end{tabular}

Mixed: adhesive and cohesive in dentin followed by Scotchbond Multi Purpose Plus and Prime \& Bond NT, which were statistically similar to each other ( $\mathrm{p}>0.05$ ). Optibond Solo and Prime \& Bond NT as well as Etch \& Prime 3.0 and Optibond Solo were, respectively, statistically similar to each other $(\mathrm{p}>0.05)$.

The examination of the debonded specimens under a stereomicroscope (Zeiss, model MC 63A, Germany) at $20 \mathrm{X}$ magnification showed that the majority of failures were adhesive for Optibond Solo, Prime \& Bond NT and Etch \& Prime 3.0 adhesive systems at 1 day, 3 months and 6 months. For Clearfil Liner Bond $2 \mathrm{~V}$ adhesive system, the majority of failures were mixed at 1 day, 3 months and 6 months (Table 4).

It was observed with scanning electron microscopy that Clearfil Liner Bond 2V (Figure 1), Scotchbond Multi Purpose Plus (Figure 2) and Optibond Solo (Figure 3) penetrated into dentin tubules, and the substrate or the surface was fractured. Prime \& Bond NT (Figure 4) and Etch \& Prime 3.0 (Figure 5) did not effectively penetrate the dentin tubules, many of which were totally or partially open.

\section{DISCUSSION}

In vitro tests attempt to simulate the clinical situation under laboratory conditions. Sometimes immediate results are obtained, but the effect of storage over time is not investigated, erroneously evaluating efficiency of the adhesive system. Therefore, tests that try to age the specimens by storing immersed in water are necessary. Bovine dentin was used in this study because it is histologically similar to the human substrate. Nakamichi et al. (11) previously compared these substrates with different restorative materials and confirmed that they demonstrated no statistical differences from each other.

In this study, the lowest shear bond strengths, for all periods evaluated, were obtained for Etch \& Prime 3.0 and were similar to those obtained with Prime \& Bond NT after 1 day and Optibond Solo at 6 months (Table 3). This result may be due to an incomplete infiltration of the acidic monomer and dissolution of the smear layer occurred in specimens (Figure 5). Sinhoreti et al. (12) also related partial dissolution of the smear layer with some closed dentinal tubules, resulting in low shear bond strength.

Clearfil Liner Bond 2V that contains 10- 


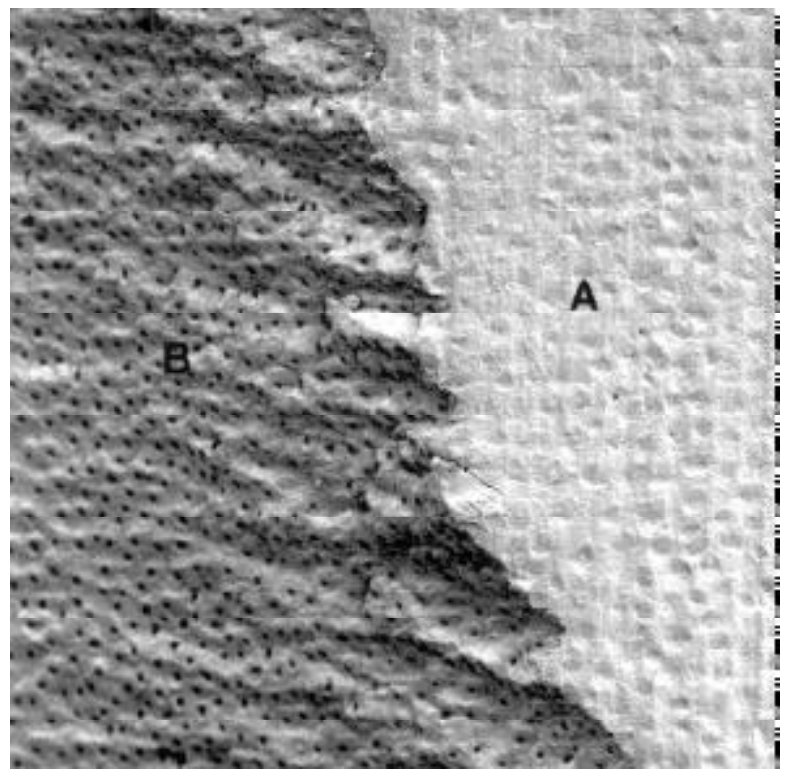

Figure 1. Morphologic aspect of debonding area using Clearfil Liner Bond 2V (500X magnification). Mixed failure type observed. Region A: adhesive system totally closing dentinal tubules; region B: cohesive failure of dentin.

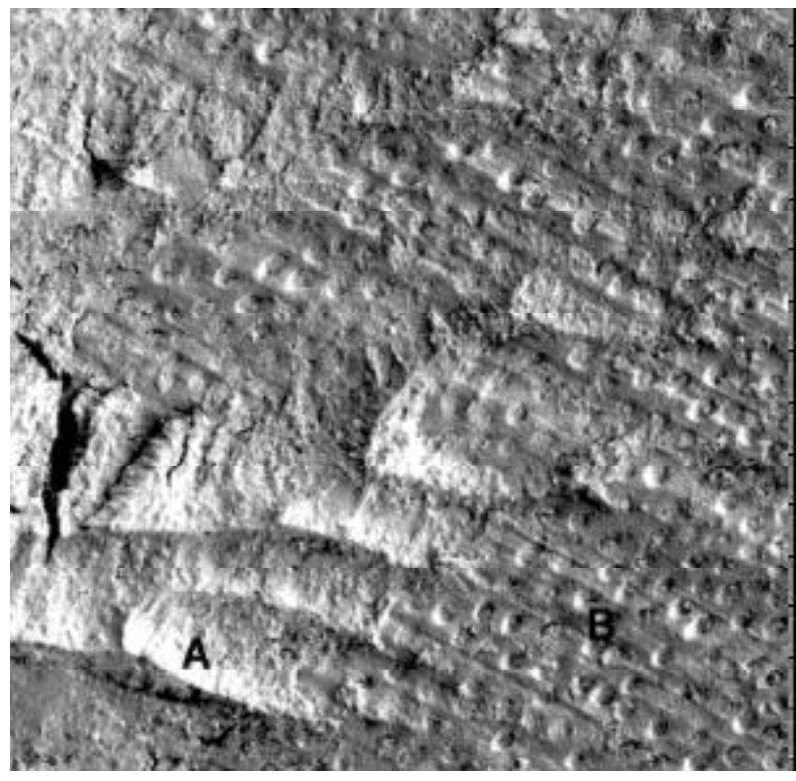

Figure 3. Morphologic aspect of debonding area using Optibond Solo (500X magnification). Cohesive failure on adhesive layer observed. Region A: adhesive closing dentin tubules; region B: adhesive remaining on dentinal surface.

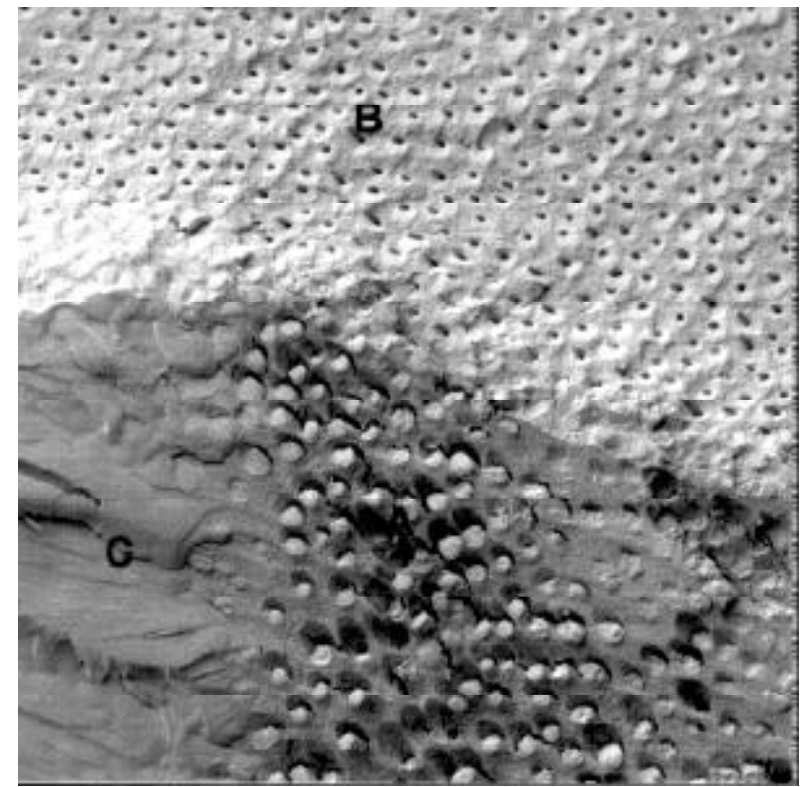

Figure 2. Morphologic aspect of debonding area using Scotchbond Multi Purpose (500X magnification). Mixed failure type observed. Region A: adhesive closing dentin tubules; region B: fracture on dentin; region $\mathrm{C}$ : adhesive remaining on dentinal surface.

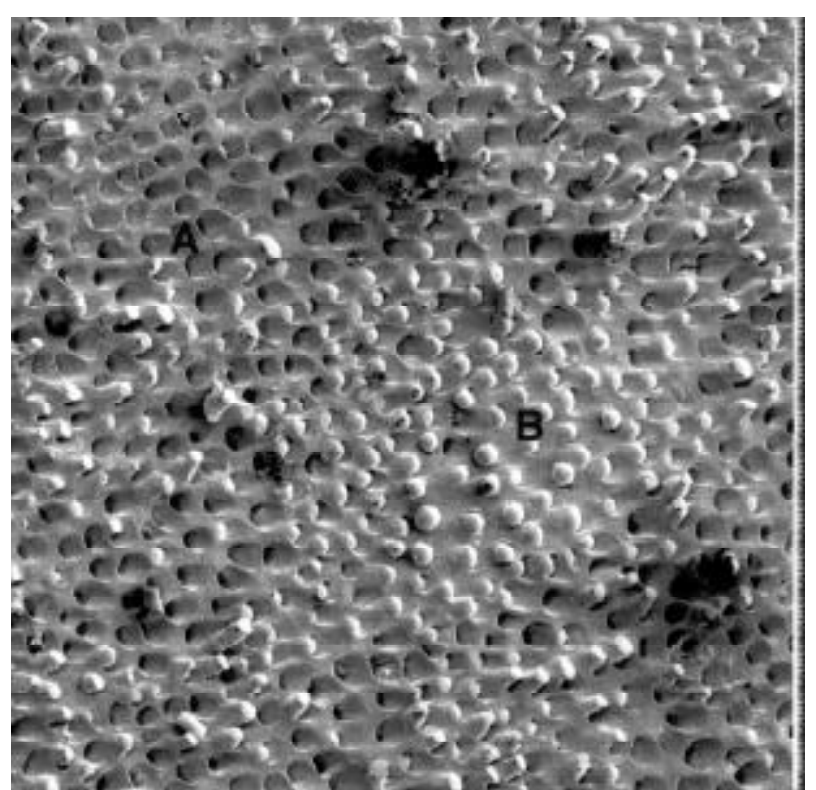

Figure 4. Morphologic aspect of debonding area using Prime \& Bond NT (500X magnification). There is no complete penetration of dentinal tubules, agglomerating by itself and preventing good wetting on demineralized dentin. Region A: opened dentinal tubules; region B: agglomeration of adhesive system on the top of dentinal tubules. 


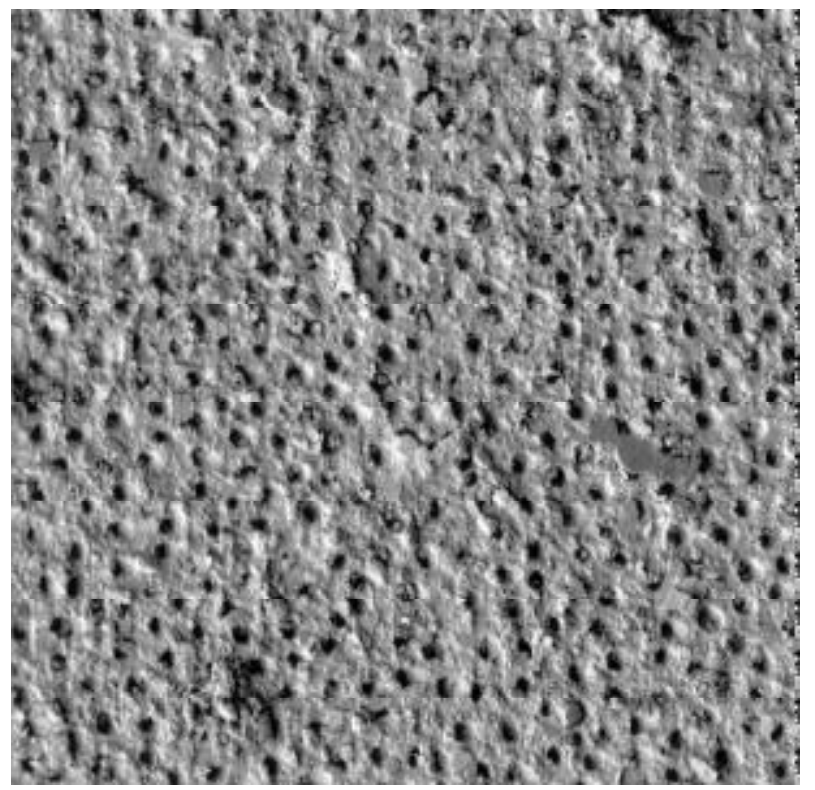

Figure 5. Morphologic aspect of debonding area using Etch \& Prime 3.0 (500X magnification). There is no total removal of smear layer and consequently deficient penetration on dentin.

MDP (10-methacrylodecamethylene phosphoric acid), another acidic monomer, seems to be more effective in forming strong shear bonding, achieving the highest means for all times tested (Table 3 ) in comparison to the other systems, corroborating previous values reported by Spohr et al. (13). The hybrid layer formed by this bond system is slightly thinner compared to other systems that use a previous acid etching step. This may be attributed to the chemical composition of this system and may explain the high percentage of mixed failures (Table 4, Figure 1) of this bond system. The $\mathrm{pH}$ neutralization of the acidic monomers, which occurred during the self-completion penetration of the reaction, produces dentinal demineralization only to the depth of penetration of the conditioning system, minimizing the formation of a collagen-rich zone at the base of the hybrid layer and decreasing the possibility of the occurrence of nanoleakage (14).

Zhang et al. (15) reported that the use of acids for the required period in the etching step did not modify the mechanical properties of the dentine matrix; however, after long storage periods in water these properties may be affected, decreasing durability.

Some authors claim that the collagen-rich zone is the weakest point of the bond. Since this zone is unprotected by minerals or resin, it is more susceptible to proteic hydrolysis (6-8). Sano et al. (9) observed high porosity at the base of the hybrid layer in an in vivo study. Watanabe and Nakabayashi (16) used an experimental primer containing phenyl-P dissolved in TEG-DMA (triethyleneglycol dimethacrylate) trying to eliminate this collagen-rich zone, but its mechanical properties were weakened after storage in water and results obtained were not satisfactory.

The failure types found in this study may be a result of the methodology used. Burrow et al. (8) and Sano et al. (9) used tensile and microtensile tests, respectively, with different types of mechanical load on the substrate to compare shear strength. It appears to be evident that the histological complex of the bonded areas is probably more resistant to shear load than tensile load.

The lower values obtained in this study may be explained by the methodology used. The use of metallic tape seems to create a less complex mechanical load and debonding occurs as a result of sliding along the interface between the adhesive layer and dentin as a result of the high concentration of the tangential force, similar to that found in the inclined plane (10).

Prime \& Bond NT had the lowest means of shear bond strength, probably due to the concentration of resinous material on the top of the dentinal tubules. Colloidal silica, in nanometric size, is used as the filler in this adhesive system. In this form, it has a high surface energy, agglomerating by itself and preventing good wetting on demineralized dentin (17). Figure 4 shows the incomplete penetration of this adhesive system into dentinal tubules that may be due to this phenomenon.

Scotchbond Multi Purpose Plus had lower shear bond strengths than Clearfil Liner Bond 2V. The primer of this adhesive system consists of HEMA (2-hydroxyethyl methacrylate) and co-monomers of polyalkenoic acid, allowing a more effective penetration. In Figure 2, it may be observed that there are fewer open tubules and cohesive fractures of dentin, indicating good penetration and retention.

In terms of storage time, shear bond strength decreased over time only when Optibond Solo was used. Some studies explain that the presence of water may degrade polymeric material $(18,19)$ and collagen fibrils that are not involved by the bond system. Optibond Solo contains colloidal silica in micrometric size which impedes penetration into demineralized dentin. Therefore, water may have penetrated and degraded the 
collagen fibrils and resinous material and the photomicrographs further support this explanation, since there were no cohesive failures in dentin (Figure 3). The other adhesive systems, with the exception of Clearfil Liner Bond $2 \mathrm{~V}$, which presented the highest bond strengths at 3 months, did not present any statistically significant differences between the times tested. In this case, if bonding was degraded by water storage, the methodology and statistical test employed were not capable of detecting this influence.

Three of the five adhesive systems evaluated showed a tendency toward higher means at 3 months (Table 2). It seems that this storage period is not sufficient to cause perceptible bonding degradation. However, this tendency towards higher strength means at 3 months of storage may be attributed to the release of stress generated during polymerization contraction(20).

Thus, the present study showed that the bond strength after different storage periods in distilled water was influenced by the adhesive system used. Further investigation under similar conditions using other adhesive systems would be beneficial.

\section{ACKNOWLEGDEMENTS}

To CAPES (Coordenação de Aperfeiçoamento de Pessoal de Nível Superior) for financial support and to Mr. André Figueiredo Reis for grammatical review.

\section{RESUMO}

O propósito desse estudo foi avaliar o efeito da armazenagem em água ( 1 dia, 3 meses e 6 meses) sobre a resistência da união ao cisalhamento sobre a dentina bovina de cinco sistemas adesivos. Para isto, 150 incisivos bovinos foram desgastados até que áreas de no mínimo $5 \mathrm{~mm}$ de dentina fossem expostas. Uma área circular de $4 \mathrm{~mm}$ de diâmetro foi demarcada para ser tratada com os seguintes sistemas adesivos: Clearfil Liner Bond 2V (CLB2V), Scotchbond Multi Uso Plus (SBMP), Prime \& Bond NT (PBNT) e Etch \& Prime 3.0 (E\&P). Para a realização do teste, uma restauração de compósito (Z100) foi realizada em formato cilíndrico na superfície tratada. Após armazenagem em água a $37^{\circ} \mathrm{C}$, as amostras foram testadas em uma máquina de teste Instron. Os resultados foram submetidos à análise de variância e ao teste Tukey com 5\% de significância. SBMP, PBNT e E\&P não apresentaram diferenças estatísticas em todos os períodos de armazenagem $(\mathrm{p}>0,05)$. CLB2V apresentou a maior média em 3 meses o qual não diferiu estatisticamente do período de 6 meses ( $p>0,05)$. Em adição, CLB2V obteve maiores médias em todos os períodos testados. SOLO obteve a menor média aos 6 meses, o qual diferiu estatisticamente dos períodos de 3 meses e 1 dia.

\section{REFERENCES}

1. Buonocore MG. A simple method for increasing the adhesion of acrylic filling materials to enamel surfaces. J Dent Res 1955;34:849-853.

2. Fusayama T, Nakamura M, Kurosaki N, Iwaku M. Non-pressure adhesion of a new adhesive restorative resin. J Dent Res 1979;58:1364-1370.

3. Nakabayashi N, Kojima K, Masuhara E. The promotion of adhesion by the infiltration of monomers into tooth substrates. J Biomed Mater Res 1982;16:265-273.

4. Van Meerbeek B, Inokoshi S, Braem M, Lambrechts P, Vanherle G. Morphological aspects of the resin-dentin interdiffusion zone with different dentin adhesive systems. J Dent Res 1992;71:15301540 .

5. Buonocore MG, Wileman W, Brudevold F. A report on a resin composition capable of bonding to human dentin surfaces. J Dent Res 1956;35:846-851.

6. Kiyomura M. Bonding strength to bovine dentin with 4-META MMA-TBB resin: Long term stability and influence of water. J Jpn Soc Dent Mater Dev 1987;6:860-872.

7. Kato G, Nakabayashi N. The durability of adhesion to phosphoric acid etched, wet dentin substrates. Dent Mater 1998;14:347-352.

8. Burrow MF, Satoh M, Tagami J. Dentin bond durability after three years using a dentin bonding agent with and without priming. Dent Mater 1996;12:302-307.

9. Sano H, Yoshikawa T, Pereira PN, Kanemura N, Morigami M Tagami J. Long-term durability of dentin bonds made with a selfetching primer, in vivo. J Dent Res 1999;78:906-911.

10. Sinhoreti MAC, Consani S, Goes MF, Correr Sobrinho L. Influence of loading types on the shear strength of the dentin-resin interface bonding. J Mater Sci 2001;12:39-44

11. Nakamichi I, Iwaku M, Fusayama T. Bovine teeth as possible substitute in the adhesion test. J Dent Res 1983;62:1076-1081.

12. Sinhoreti MAC, Lopes MB, Konno ANK, Correr Sobrinho L, Consani S. Aspectos morfológicos e resistência ao cisalhamento em função dos condicionantes de esmalte e dentina. Pós-grad Rev Fac Odontol São José dos Campos 2000;3:20-28

13. Spohr AM, Conceição EM, Pacheco JF. Tensile bond strength of four adhesive systems to dentin. Am J Dent 2001;14:247-251.

14. Sano H, Takatsu T, Ciucchi B, Horner JA, Mathews WG, Pashley DH. Nanoleakage: Leakage within the hybrid layer. Operative Dent 1995;20:18-25.

15. Zhang Y, Agee K, Nor J, Carvalho R, Sachar B, Russell C, Pashley D. Effects of acid-etching on the tensile properties of demineralized dentin matrix. Dent Mater 1998;14:222-228.

16. Watanabe I, Nakabayashi N. Bonding durability of photocured phenyl-P in TEGDMA to smear layer-retained bovine dentin Quintessence Int 1993;24:335-342.

17. Tay FR, Moulding KM, Pashley DH. Distribution of nanofillers form a simplified-step adhesive in acid conditioned dentin. J Adhes Dent 1999;1:103-117.

18. Calais JG, Soderholm KJ. Influence of filler type and water exposure on flexural strength of experimental composite resins. J Dent Res 1988;67:836-840.

19. McKinney JE, Wu W. Chemical softening and wear of dental composites. J Dent Res 1985;64:1326-1331.

20. Øilo G, Austrheim EK. In vitro quality testing of dentin adhesives. Acta Odont Scand 1993;51:263-269.

Accepted March 11, 2002 